\title{
GIS and people with visual impairments or blindness: Exploring the potential for education, orientation, and navigation
}

\author{
R DAN JACOBSON AND ROBERT M KITCHIN
}

\author{
School of Geosciences, Queen's University of Belfast, Belfast, BT7 1NN, UK. \\ e-mail: D.Jacobson@qub.ac.uk
}

\begin{abstract}
GIS, with their predominantly visual communication of spatial information, may appear to have little to offer people with visual impairments or blindness. However, because GIS store and manage the spatial relations between objects, alternative, nonvisual ways to communicate this information can be utilized. As such, modified GIS could provide people with visual impairments access to detailed spatial information that would aid spatial learning, orientation, and spatial choice and decision making. In this paper, we explore the ways that GIS have been, and might be, adapted for use by people with visual impairments or blindness. We review current developments, report upon a small experimental study that compares the ability of GIS-based and various adaptive technologies to communicate spatial information using non-visual media, and provide an agenda for furure research. We argue that adapted GIS hold much promise for implicitly improving the quality of life for visually impaired people by increasing mobility and independence.
\end{abstract}

\section{Introduction}

Whether blind, visually impaired, or sighted, our quality of life is greatly dependent on our ability to make informed spatial decisions through the processing and synthesis of spatial information, within a variety of situations, at differing scales (Golledge 1993). Given this necessity, to varying extents, we all have a spatial awareness of our surroundings. This awareness is derived through our senses as we engage in direct perception of environments that are close enough to touch, taste, smell, hear, and see. These senses work at varying scales. For example, touch, taste, and smell tend to work within haptic, or body, spaces. Sight and hearing help collect data from greater ranges. To collect spatial information relaring to spaces that are not directly encountered, or to supplement direct encounters, there are a range of secondary sources available for consultation, for example books, television, radio, newspapers, and maps.

Within the process of gaining spatial knowledge, sight is often termed the sense 'par excellence' (Foulke 1983). As a result, it is widely contended that people with severe visual impairment or blindness experience a world different from people who are sighted (see Spencer et al 1989). This has led researchers such as Golledge (1993) to argue that beyond communicating by reading and writing, the inability to travel independently and to interact with the wider world is the most significant problem produced by visual impairment or blindness. Indeed, Bruce et al (1991) found in a survey of young people registered blind in the United Kingdom that in the preceding week, 20 percent of respondents had not left their home, only 34 percent had travelled locally, and only 41 percent left the confines of the home alone and on foot. Similarly, Clark-Carter et al (1986) reported that at least 30 percent of people with visual impairment or blindness make no independent journeys outside their home, and that most of those who do venture outside their home independently adhere to known routes, as exploration can lead to disorientation and chaos, accompanied by the fear, stress, and panic associated with being lost (Golledge 1993; Hill et al 1993). For people with visual impairments or 


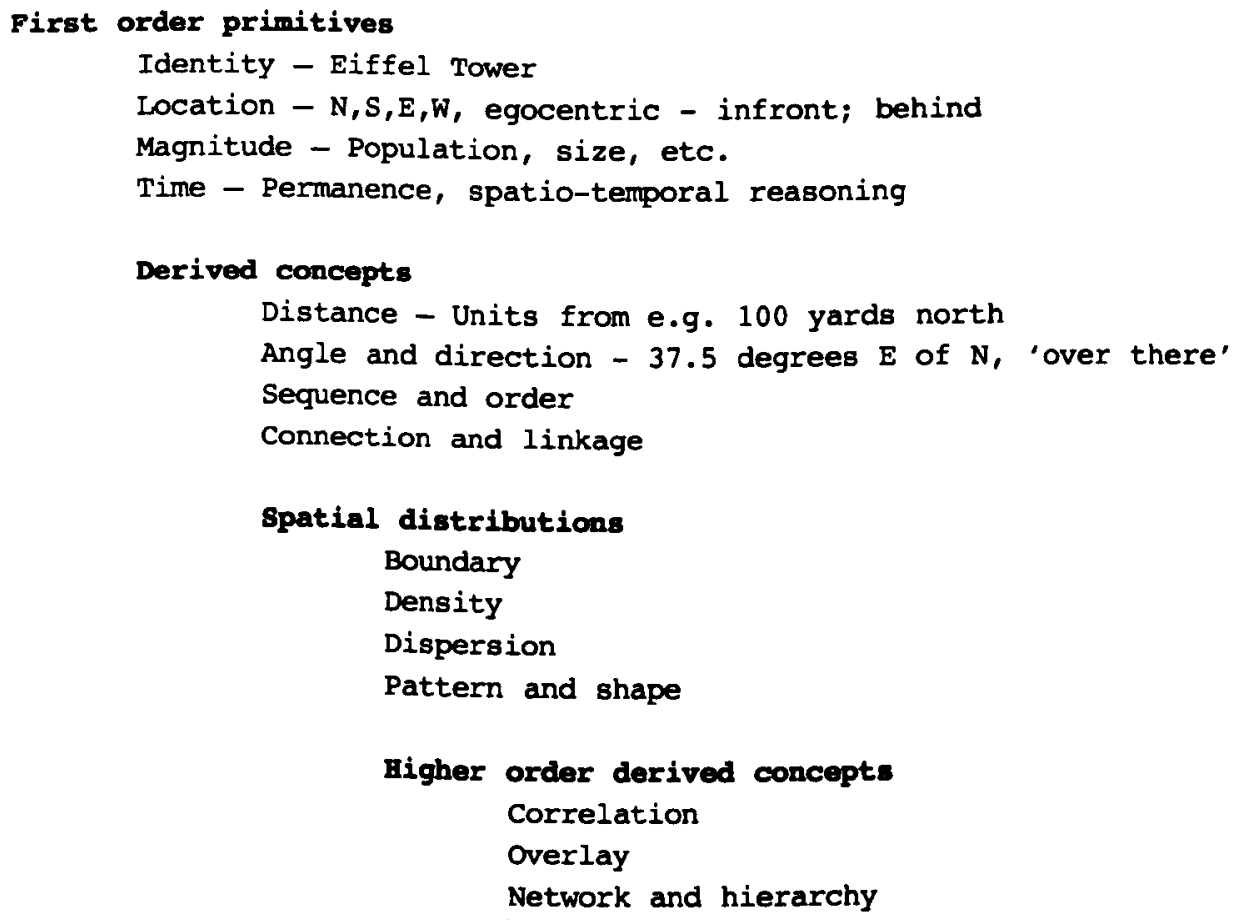

Table 1. Spatial primitives (Golledge 1995: 179).

blindness, access to the geographic world is limited - they have to rely on their remaining auditory, tactile, olfactory, and kinaesthetic (sensorimotor feedback from locomotion) senses to gather information about the world. The environment they are able to perceive has relatively few, unique, locational cues; tactile cues like kerb lines are often repeating; and auditory or olfactory cues may be temporal and ephemeral. As such, there is a need to develop effective methods of communicating spatial information using a non-visual medium in order to improve their quality of life through increased mobility and independence.

The geographic environment is multifaceted, dynamic, and complex. Communicating the complexity of this environment to people who are unable to use vision, and may never have seen the world, is fraught with problems. GIS, with their predominantly visual communication of spatial information, may, at first, appear to have little to offer people with visual impairments. However, a GIS, with a suitably adapted interface that can communicate spatial information non-visually, has the potential to work as a spatial tool, assisting a visually impaired or blind person in the learning and 'reading' of spatial concepts from both primary and secondary sources. Here, a GIS could either be utilized as a multimedia host for the presentation and learning of secondary data such as maps (Fanstone 1995; Jacobson 1996) or as a portable navigation aid (in conjunction with a global positioning system (GPS) (Golledge et al 1991; Petrie et al 1996). As such, an adapted GIS could have great utility in both teaching the spatial relations of an environment before it is encountered, and guiding a visually impaired person through an environment as they actually traverse it. In this paper, we explore the ways that GIS have been, and might be, adapted for use by people with visual impairments or blindness, detailing the attributes an adaptive GIS must incorporate. In addition, we report upon a small study which compared the utility of such a system to other adaptive technologies.

\section{Cognitive map knowledge as an internal GIS}

If a GIS is defined simply as a tool for capturing, manipulating, displaying, querying, and analysing information of a spatial nature (Burrough 1986), 
then there is a strong coincidence of functionality between a GIS and human cognitive mapping abilities (Golledge et al 1995). Golledge et al (1994) suggest that the spatial reasoning and inference capabilities of humans can be considered crudely as an internalized GIS. However, how does this internalized GIS work to gather, store, and synthesize spatially referenced information with limited or no vision? At present, the answer to this question is contested. It is clear that at a perceptual level, a visually impaired person's sensory impairment limits the gathering of information from both primary and secondary sources. For example, a blind person traversing an unfamiliar town is unable to read street signs that can be read by people with vision. What is unclear, however, is the extent to which a blind person's understanding of place has spatial reference.

Golledge (1995) outlines the key spatial building blocks that people use to conceptualize the geographic environment (Table 1). In essence, these spatial primitives can be considered the 'inputs' to someone's cognitive map knowledge (an internal construct of everyday geographic space (Kitchin 1994)). If the geographic environment is considered a physical reality, then a comprehension of this reality is held in an abstracted, distorted, filtered, and timereferenced manner in cognitive map knowledge. There is much debate in the literature as to the ability of congenitally blind people (blind from birth) to comprehend space. Proponents of the deficiency theory argue that congenitally blind individuals are unable to develop spatial understanding because they have never experienced the perceptual processes (e.g. vision) necessary to comprehend two- and threedimensional arrangements, scale changes, and more complex concepts such as hierarchy, pattern, and continuity (see Golledge 1993). Inefficiency theory states that people with visual impairments can understand and mentally manipulate spatial concepts, but because information is based upon auditory and haptic cues this knowledge and comprehension is inferior to that based upon vision (see Spencer et al 1989). Difference theory states that visually impaired individuals possess the same abilities to process and understand spatial concepts as non-visually impaired individuals, and that any differences, either in quantitative or qualitative terms, can be explained by intervening variables such as access to information, experience, or stress (Passini and Proulx 1988;
Golledge 1993). Most researchers now acknowledge that both congenitally and adventitiously blind and visually impaired individuals can process spatial data, although their ability is variable and generally poorer than that of sighted individuals. The scientific bases of these theories are complicated because of issues relating to residual vision, the non-consistent and varying use of different measurement techniques, and differing environmental and laboratory conditions during tests (see Kitchin and Jacobson 1997). In addition, it is not clear whether the theories relate to congenital blindness alone or also include adventitious blindness.

The weight of current opinion rests with the difference theory. This theory suggests that people with visual impairments employ spatial reasoning that manipulates spatial relations in some form. As such, an internalized GIS might operate through the use of image cognition or spatial language. Image-based cognition means that knowledge retains the relative positions of places within a single frame. Language-based cognition means that spatial relations are retained within propositional coding (e.g. A is above $B ; A$ is further away from $B$ than $C$ is). This propositional-based spatial system would allow quite sophisticated spatial reasoning, including inferences (e.g. if we know that $A$ is above $B$ by so far and $C$ is to the right of $B$ by so far we can infer the short-cut route from $A$ to $C$ ).

At present, then, there appear to be two possible means in which to develop a non-visual medium of spatial communication. One method is to try and develop a system based upon touch that conveys relative spatial relations. The second method is to try and develop a system based upon spatial language. In a sense, to develop a 'talking' medium. Both methods of language and touch have been utilized in trying to create non-visual technologies to convey spatial information, including those which utilize a GIS as an underlying spatial database.

\section{Communicating spatial information to people with visual impoirments}

While there are possibilities to develop sophisticated sight-compensating technologies, at present, most current technical aids merely seek to add environmental cues to the information already gathered through auditory, tactile, olfactory, and 
kinaesthetic means. These range from the simple white cane (touch and sound), to more sophisticated aids such as the 'hoople' (a modified cane - touch and sound) (Ellis 1995), ultrasound sonic guide (sound) (Kay 1973; Spungin 1985), Pathfinder (sound) (Joffee 1987; Uslan et al 1988), and laser cane (sound) (Aurlan 1996). Lee (1996) is currently working towards a 'logical sensor' where several types of sensors work together, validating and compensating for one another. These particular aids only assist mobility within the immediate vicinity of the user. They provide no contextual frame of reference concerning information from further away or information relating to orientation for use in planning travel (Golledge et al 1989).

For orientation, simple beacon-like devices have been developed which transmit audio information to guide blind pedestrians along a route with users following a chain of beacons (see Brabyn 1995). While devices such as beacons do provide more information concerning orientation, there are infrastructure problems such as the number and cost of installation. For example, Manchester City Council would need to buy a minimum of 18000 beacons to attach to its bus stops alone, not including beacons to guide users along pedestrian routes to each bus stop. Further, potential users also need to have a priori cognitive awareness of the beacons' locations. To compensate for the lack of cognitive awareness, these simple mobility aids have been supplemented by simple learning devices such as tactile maps designed to aid users learn a route or area before exploring it (Golledge et al 1991; Jacobson 1996).

In recent years, there has been the development of more sophisticated technological aids which utilize advances in computing. These devices aim to be more reactive, providing more attendant information at wider scales, utilizing detailed relational, spatial databases. As such, all these devices use GIS databases to facilitate their use. These devices can generally be divided into those which are orientation and mobility aids (e.g. personal guidance systems and 'talking maps') and those which are learning aids (e.g. NOMAD - an audio-tactile graphics processor (Parkes 1988) - and multimedia, hypertext systems). Devices within the orientation and mobility category tend to use language interfaces, whilst those in the learning category use a mixture of both tactile and language media. It is important to remember that these technologies are not intended to replace 'simpler' mobility aids but rather to supplement them. For example, users of a personal guidance system would still use their white cane. The cane would provide local, immediate guidance in relation to specific objects and the personal guidance system would provide the macro, contextual information, aiding orientation, spatial decision making, and travel planning.

\subsection{GIS-based navigation aids}

GIS-based navigation aids include personal guidance systems and 'talking map' devices. Both

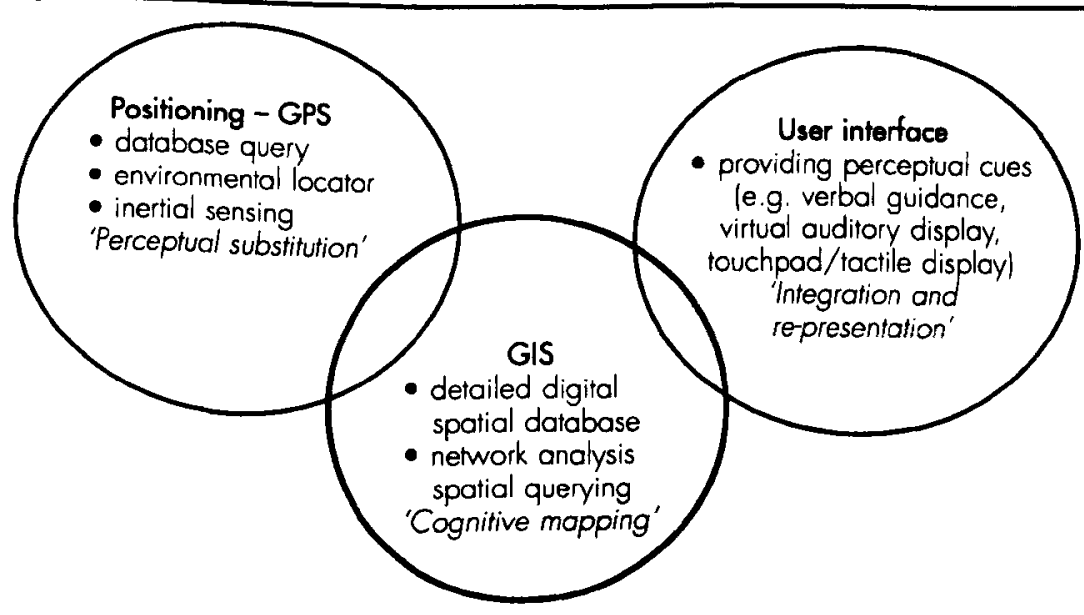

Figure 1. Conceptual framework of navigation aids. 
types of aid utilize sophisticated spatial databases that can be queried by the user to make informed navigation decisions. As such, each device utilizes a strategy which aligns itself with how we make spatial decisions (Figure 1). First, it uses some sort of locating technology to determine current location (e.g. a GPS, or it might be self-reported). Second, it uses a spatial database and query algorithms to mimic the cognitive map knowledge of an area. Last, it aids decision making by allowing the integration and manipulation of data so that user queries can be processed using a specialized interface.

A number of research teams are exploring the development of personal guidance systems (Golledge et al 1991; Petrie et al 1996). The first pioneering personal guidance system, conceptually proposed by Loomis (1985), was designed, developed, and made operational by a team of geographers and psychologists at the University of California at Santa Barbara (see Golledge et al 1991 and Loomis et al 1995). Their Personal Guidance System (PGS) comprises three modules: a locator unit, a detailed spatial database (GIS) containing an algorithm for path selection, and a user interface (Figure 2). The interface of the PGS is a virtual auditory display (Loomis et al 1990). Here, the labels of the objects within 'real space' such as 'tree', 'path', 'library', and so on are spoken through a pair of headphones and appear as virtual sounds at their correct locations within the auditory space of the traveller. As such, objects appear to 'announce' themselves with the sound emanating from the geographic location of the landmark. There are, however, some minor technical problems involving the externalization of the sound (Loomis et al 1995).

The PGS circumvents some of the more troublesome aspects of spatial language in conveying spatial relations by adopting a system whereby virtual space is overlaid on real space. Figure 3 illustrates the concept of virtual auditory representation as a traveller approaches a telephone booth. The PGS has evolved into a fully functional system, adapted so a naïve, untrained novice can use the system, and is an example of a 'naive' GIS.

The problem of deciding which information to present to a blind user has been overcome by using common GIS techniques: buffering and corridoring. For example, a buffer of a predetermined size is created around the user. Any features which fall within the buffer 'call' the user as if sited in their real location. This feature allows visually impaired users access to the macro environment normally experienced by vision. Features can be given a salient value within the database, so those which pose the greatest danger, or are of particular interest, are highlighted first. In addition to buffering, whole routes can be corridored. If the traveller veers from the desired route by leaving the corridor, an error is signalled and directions for return provided. At present, the user interacts with the system by using a small keypad. In the future it is hoped that interaction will be speech controlled.

MoBIC (Mobility of Blind and elderly Interacting with Computers), a European consortium, has developed MoTA (Mobic Travel

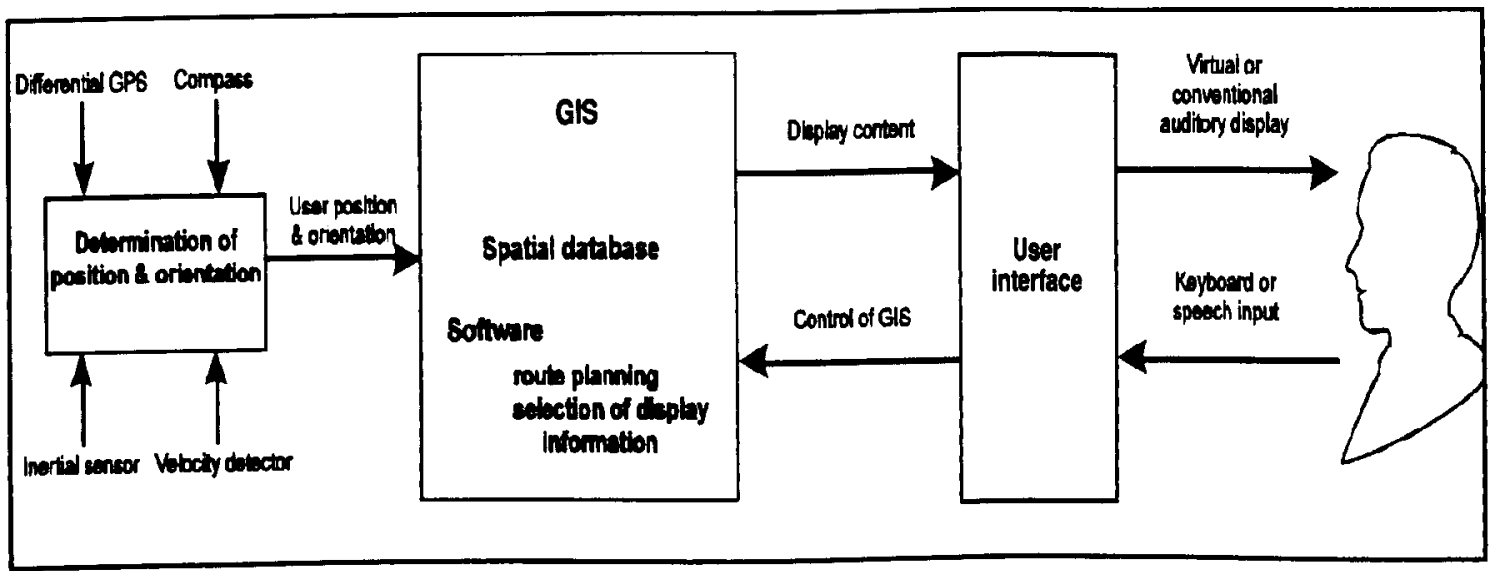

Figure 2. Personal Guidance System (PGS) as developed by Santa Barbara group (Loomis et al 1995). 


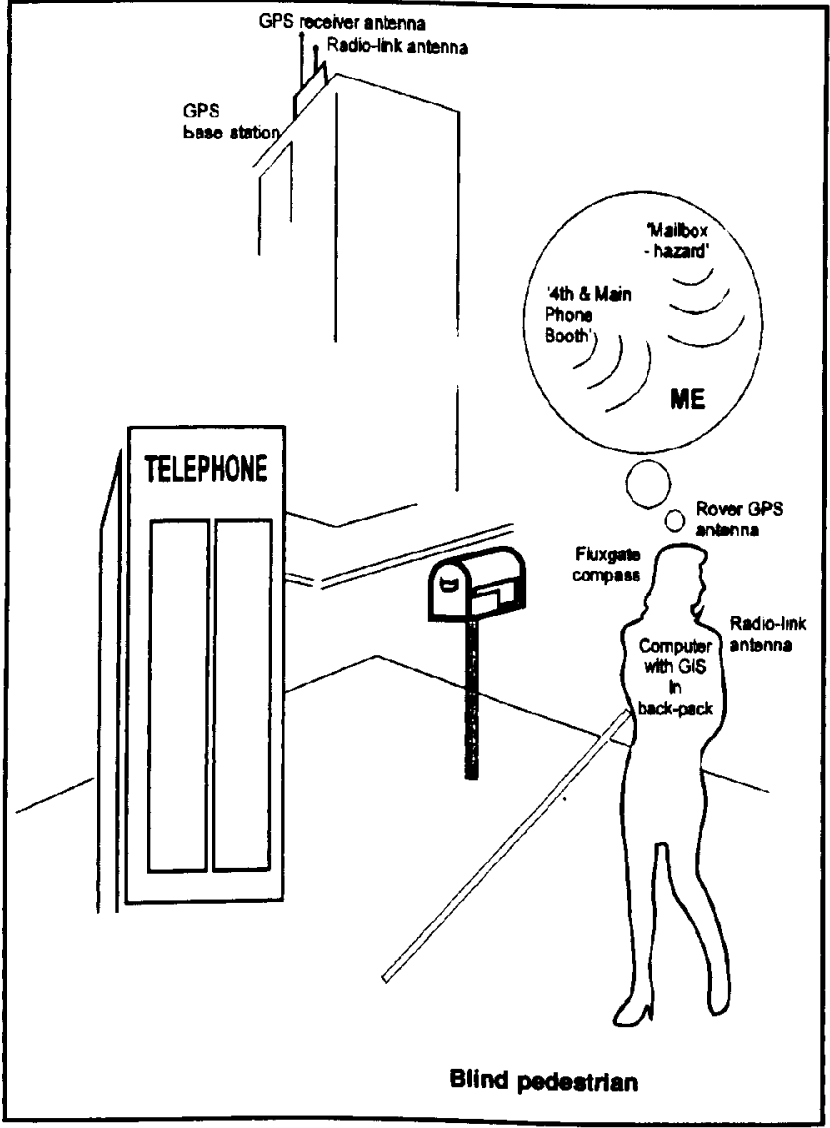

services, and to find out the names and layout of roads (Gill 1996).

A third system, 'Atlas Speaks/Atlas Strider', combines a talking map system with a GPS positioning device. 'Atlas Speaks' features a customized street network database through which the user is able to navigate in a prejourney mode, listening through an audio interface to a commentary of the streets which consists of his/her route. In the field, a small GPS receiver communicates with the database (carried in a satchel-sized bag) giving the user positional information to an accuracy of 80-100 $\mathrm{m}$ (due to selective availability), along with information about landmarks and preprogrammed waypoints. The system offers the user the ability to add data or points of interest to the database via a Braille keypad and the positioning capability of the GPS receiver. The interface, as with the MoBIC system, is entirely language based, although in 'Atlas Speaks' the output can be configured to miles, streets, blocks, or compass points. 'Atlas Speaks', is commercially available, and its portable positioning component, 'Atlas Strider' is soon to be released commercially, operating from a lightweight $5 \mathrm{~kg}$ satchel.

Both the MoTA and Atlas Speaks/Atlas

Figure 3. Virtual auditory display in Personal Guidance System (PGS) (Golledge et al 1994).

Aid). MoTA is conceptually similar to the PGS developed by the Santa Barbara group as both systems incorporate GIS and GPS elements. However, the MoTA system consists of two units, MoPS (the MoBIC Pre-journey System) to assist in the planning of journeys, and MoODS (the MoBIC OurDoor System) to provide users with orientation and navigation assistance during journeys (Strothotte et al 1996). The intended full functionality of the MoTA system is outlined in Table 2. From March to September 1996, MoBIC carried out its second field trial using its third prototype in Birmingham, United Kingdom, with 13 participants. Each participant received training tutorials involving map-based area exploration, planning a route, and using the outdoor system. The feedback from the participants was very positive, with respondents clearly able to use the system to find out about and explore places and
Strider' systems use a spatial language interface - the environment around the pedestrian is explained verbally (e.g. 'on your left there is a bus stop'). This spatial language representation of the geographic environment is conceptually similar to that found in early computer, adventure-style games. Table 3 shows a sample output from such a game. In these games the challenge for the player is to build a cognitive map of the area they 'travelled' through. It is hoped that blind pedestrians will be able to use a similar strategy to develop a cognitive understanding of a real-world environment. Figure 4 shows a sample output from MoODS with a visual representation to aid explanation. In MoPS the interface is similar, although the user navigates a representation of the environment using the compurer keyboard cursor keys or a specially adapted touchpad.

A general problem with personal guidance systems is the need for high data integrity. Low error rates are of paramount importance as users could be relying on their personal guidance system in 


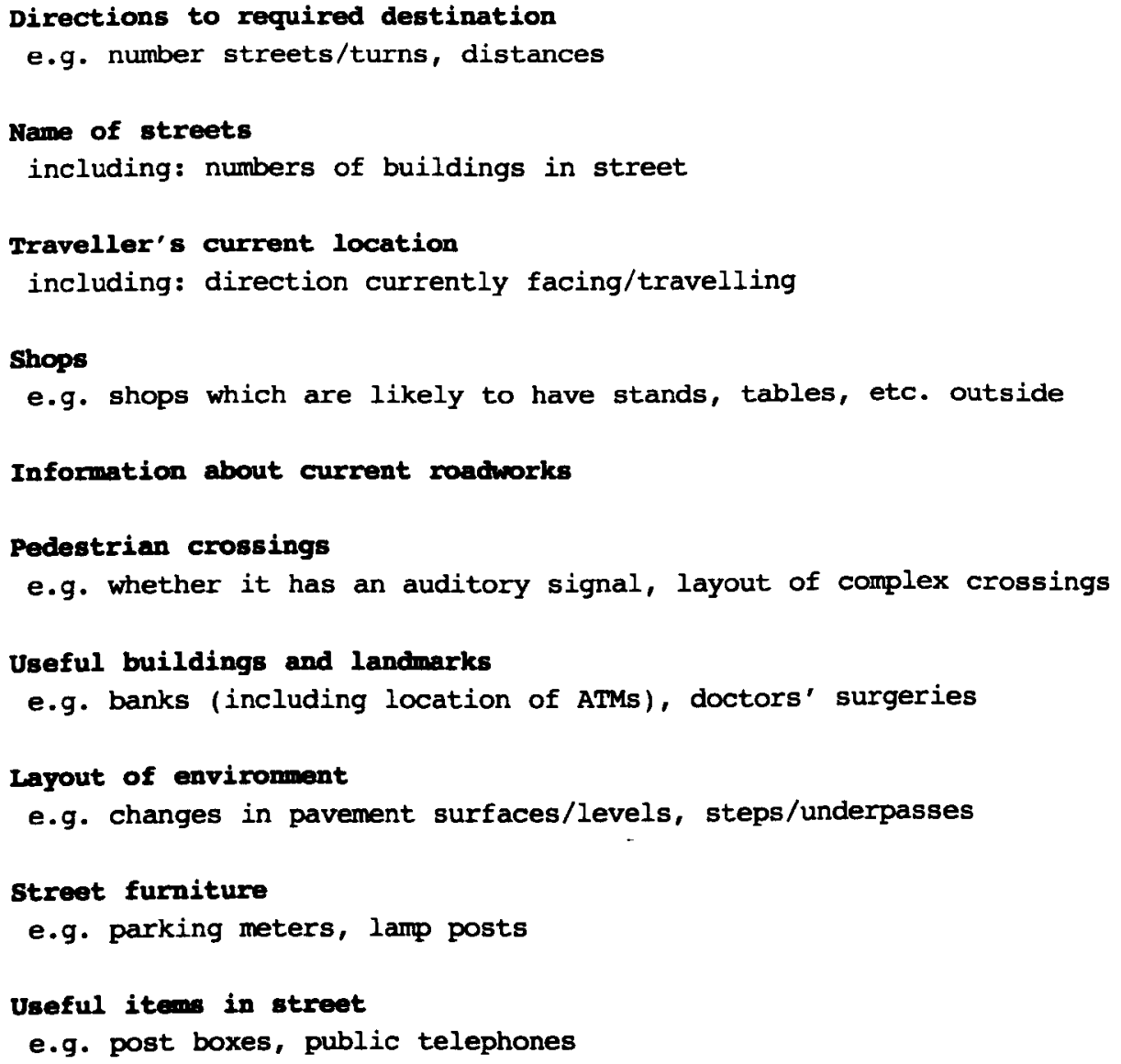

Table 2. Planned information to be provided by MoBIC Travel Aid (Strothutte et al 1996: 74).

You are in a small rural town, surrounded by rustic buildings and country folk. Obvious exits: north, south, west, and east.

$>$ mest

To the west are the crossroads at the centre of town. Roads leave the town in the four main compass directions.

Obvious exits: north, south, west, and east.

$>$ south

The road leaving the town to the south soon deteriorates to a track and descends the valley of the ootah river. At the bottom of the valley is a $T$-junction.

Obvious exits: west, east, or return north.

$>$ most

You turn westward and travel a few hundred yards across the river plain. After a while the track becames muddy.

Obvious exits: continue west or return east.

Table 3. A textual example from a computer adventure game. 
potentially critical situations, for example when crossing a road. Further, the scale of data must be large to incorporate detail such as street furniture and other obstacles that would be important for visually impaired people. However, it is important to strike a careful balance: too large a scale (e.g. every piece of street furnituri every pavement crack, etc.) and the level of det: is overwhelming and impractical; too small a scale and key information will be omitted. Regardless of scale, it is generally accepted that pre-existing data sets are not completely suitable. Database requirements such as sloping kerbs, street furniture, and ephemeral information (e.g. pavement signs, roadworks, etc.) are excluded from most large-scale data sets. Some form of additional data capture is thus needed. Golledge et al (1991) suggest 'piggybacking' this onto existing data already held by utility companies and Balachandran (1995) suggests, within the United Kingdom at least, the use of digital versions of Ordnance Survey Landline (1:1250) data. However, the widespread digitization of extra information will be both costly and, given the dynamic nature of many features of the environment, untenable. As such, systems are likely only to have utility in certain 'key' locations where suitable digital data is available and the necessary additional database adaptation has been carried out.

Spatial language interfaces also suffer from one particular problem. Spatial language is often 'fuzzy' in nature, using terms that are imprecise, inexact, hard to define, and relative (Frank and
Mark 1991). For example, consider the following words which could be given as verbal instructions: away, backwards, around, behind. Table 4 lists the spatial prepositions in the English language. These fuzzy prepositions are in general highly ambiguous, providing a cumbersome way of describing space. When given as verbal instruction from an orientation system, they are potentially extremely misleading and dangerous. The systems using spatial language as an interface rely far more on the traveller's confidence, independence, and their knowledge of their local geographic frame of reference. MoBIC users, for example, have to determine their orientation from a supplemental pocket compass. The error caused by the selective availability in the GPS signal for the positioning of the 'Atlas Strider' user ( $80-100 \mathrm{~m})$, may, in dense urban areas, cause the user to be 'positioned' a junction away from where they really are. Although all GIS-based systems are beneficial to varying degrees, MoBIC and 'Atlas Strider' may be considered route following and orientation tools, whereas PGS is a navigation system as it provides information about the distant and occluded environment in a similar manner to that obtained by a sighted individual visually scanning their surroundings.

\subsection{GIS-based learning aids}

Personal guidance systems are largely designed to aid on-route navigation. GIS technology is also being used to aid pre-route learning. GIS within this

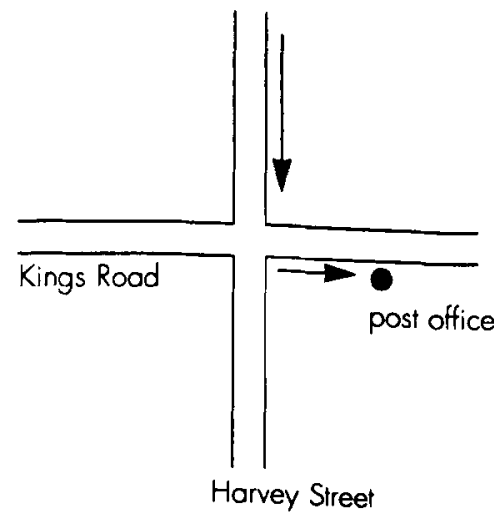

You are heading south along Harvey Street towards Kings Rood.

The crossing at Kings Road has on audible beeper and tactile pavings.

West along Kings Rood leads towards the Leisure Centre.

Eost along Kings Road leads to the town centre and shopping facilities.

Kings Road traffic is often very fast.

There is a post office to the east on the south side of Kings Road.

The post office is open from $8 \mathrm{am}$ to $4 \mathrm{pm}$.

You are heading east along Kings Road.

You are now standing outside the post office.

The entrance has protruding steps.

Figure 4. A sample output from MoBIC OutDoor System (MoODS). 


$\begin{array}{lll}\text { about } & \text { between } & \text { outside } \\ \text { above } & \text { betwixt } & \text { over } \\ \text { across } & \text { beyond } & \text { past } \\ \text { after } & \text { by } & \text { through } \\ \text { against } & \text { down } & \text { throughout } \\ \text { along } & \text { from } & \text { to } \\ \text { alongside } & \text { in } & \text { towards } \\ \text { amid|st) } & \text { inside } & \text { under } \\ \text { amonglst| } & \text { into } & \text { underneoth } \\ \text { around } & \text { near } & \text { up } \\ \text { at } & \text { nearby } & \text { upon } \\ \text { atop } & \text { off } & \text { via } \\ \text { behind } & \text { on } & \text { with } \\ \text { below } & \text { onto } & \text { within } \\ \text { beneath } & \text { opposite } & \text { without } \\ \text { beside } & \text { out } & \end{array}$

\section{Compounds}

$\begin{array}{ll}\text { far from } & \text { on top of } \\ \text { in back of } & \text { to the left of } \\ \text { in between } & \text { to the right of } \\ \text { in front of } & \text { to the side of } \\ \text { in line with } & \end{array}$

$\begin{array}{lll}\text { Intransitive propositions } & \\ \text { afterward(s) } & \text { forward } & \text { right } \\ \text { apart } & \text { here } & \text { sidewoys } \\ \text { away } & \text { inward } & \text { south } \\ \text { back } & \text { left } & \text { there } \\ \text { backward } & \text { N-ward le.g. } & \text { together } \\ \text { downstairs } & \text { homeward) } & \text { upstairs } \\ \text { downward } & \text { north } & \text { upward } \\ \text { east } & \text { outward } & \text { west }\end{array}$

Table 4. Spatial prepositions of the English language (Landau and Jackendoff 1993: 224).

framework are utilized in two main ways. First, GIS can be used as a way to store, manage, and manipulate spatial information for use in more conventional aids such as tactile maps. Coulson (1991) pioneered the use of a GIS, exploiting its cartographic functionality, for the production of tactile maps. A sighted operator would create a map, first plorted on paper then rendered tactile by microcapsule paper. The design of tactile maps offers new challenges for traditional cartographic methodologies as the finger is less sensitive than the eye, and can only be searched serially and not synoptically. This requires solutions to many traditional cartographic problems such as the amount of information presented, symbolization, generalization, and simplification. The structure of data stored on a GIS and the ways in which this can be accessed are beneficial to this map manipulation and management.

At a second level, GIS can be used as an underlying database to an audio-tactile 'multimedia' system. A common problem with tactile maps is labelling. Braille labelling is inflexible and when enough labels are applied to facilitate suitable understanding the map often becomes cluttered and illegible (Tatham 1991). Using labels in a separate legend or key reduces the immediacy of the graphic and introduces interpretative problems as referencing is disrupted (Hinton 1993). One solution has been to develop audio-based systems that link sound with touch. For example, when a raised area on a tactile map is touched a corresponding sound label is triggered. Two such systems include NOMAD (Parkes 1988) and 'talking tactile maps' (Blenkhorn and Evans 1994). Fanstone (1995) has exploited the GIS capabilities of NOMAD to build a hierarchical audio-tactile GIS of the Nottingham University campus. The GIS functionality of NOMAD is detailed in Table 5.

Recent developments with the NOMAD system (Parkes 1996) mean that visually impaired or

\author{
Orientation information - direction of north, azimuth of any \\ two points \\ Relative direction (converts north, etc. to in front, forward, etc.) \\ Distance along a stroight line \\ Distance along a continuous path \\ Hierarchical levels of information (press once, press twice for \\ next levell \\ Listen to sound tracks of a route \\ Use variation in sound to guide the user along a line \\ Use sound to infer the third dimension e.g. grodient \\ Variable scale (zoom in, zoom out to separate tactile maps) \\ Area calculations \\ What am I nearest to? \\ Take me/direct me to a point of interest
}

Table 5. GIS functionality options for NOMAD. 
blind people can not only 'read' graphics but also create their own diagrams. As such, these systems mean that GIS databases can be used by blind or visually impaired people to learn about the environment the map represents, map use, and the interpretation of maps.

\subsection{Hypermedia}

One development that has great potential is hypermedia. Hypermedia includes linked text, still imagery, moving imagery, and sound recordings. A well-known example of a hypermedia environment is the World-Wide Web. Hypermedia has been successfully used to aid user interaction with a GIS (Gardiner and Paul 1993; Linsey and Raper 1993). The hypermedia interface allows non-expert users to interact easily with GIS because the user can navigate between textual and cartographic information nodes in order to get a welldocumented, multifaceted representation of space, from varied sources and differing viewpoints within a hypermedia environment (Milleret-Raffort 1995). Following cross-references is physically clumsy

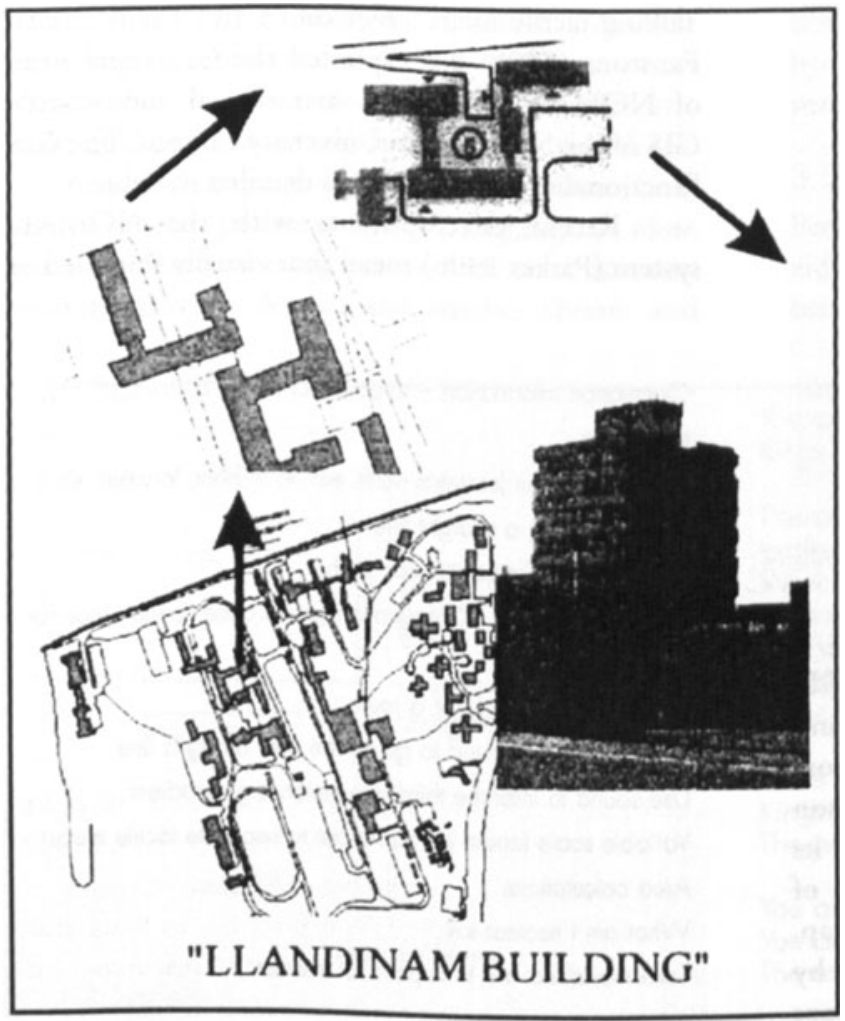

Figure 5. Visual overview of ArcView 'GIS style' system. (turning pages, searching through index, serially exploring a tactile map, etc.) in a conventional document because the intellectual structure and layout is sequential and hierarchical. A hypermedia document (if structured correctly) should allow a seamless navigation through the document, passing through various media, following a line of thought or enquiry. Conventional hypermedia systems are predominantly visual in nature. They can, however, also offer people with visual impairments a way of exploring the world.

Non-visual hypermedia systems seek to provide sensory substitution with spoken audio information replacing textual and image-based information. Such a system now exists for blind users on the Web (Webspeak 1995). Here, images are bypassed, textual information is converted to speech, and hypertext links are explained. As part of the Graphical User Interfaces for Blind People (GUIB) project, Savidis and Stephanidis (1994) used a 'rooms' metaphor (you are in a room (description of room), in front of you is a door, etc.) to successfully allow a blind or visually impaired user to traverse a virtual, three-dimensional space and build a 'non-visual realization' of that space.

\section{A comparative study of adaptive technologies}

In order to develop and evaluate some of these emergent technologies, a small research project was undertaken at the University of Wales, Aberystwyth, from 1994 to 1996. Local, visually impaired adults helped plan, develop, advise on, and then evaluate various systems. Larger trials were based at the Royal National College for the Blind at Hereford. Due to the prohibitive infrastructure problems associated with the development and maintenance of a GIS-based navigation system (related to the high cost of large-scale digital spatial data, the need to maintain a base station for differential GPS correction and 'technology heavy' equipment), it was decided to explore 'pre-journey' technologies. The main aim was to examine how existing GIS and 'GIS style' technology could be adapted to provide people with visual impairments access to spatial map-like 


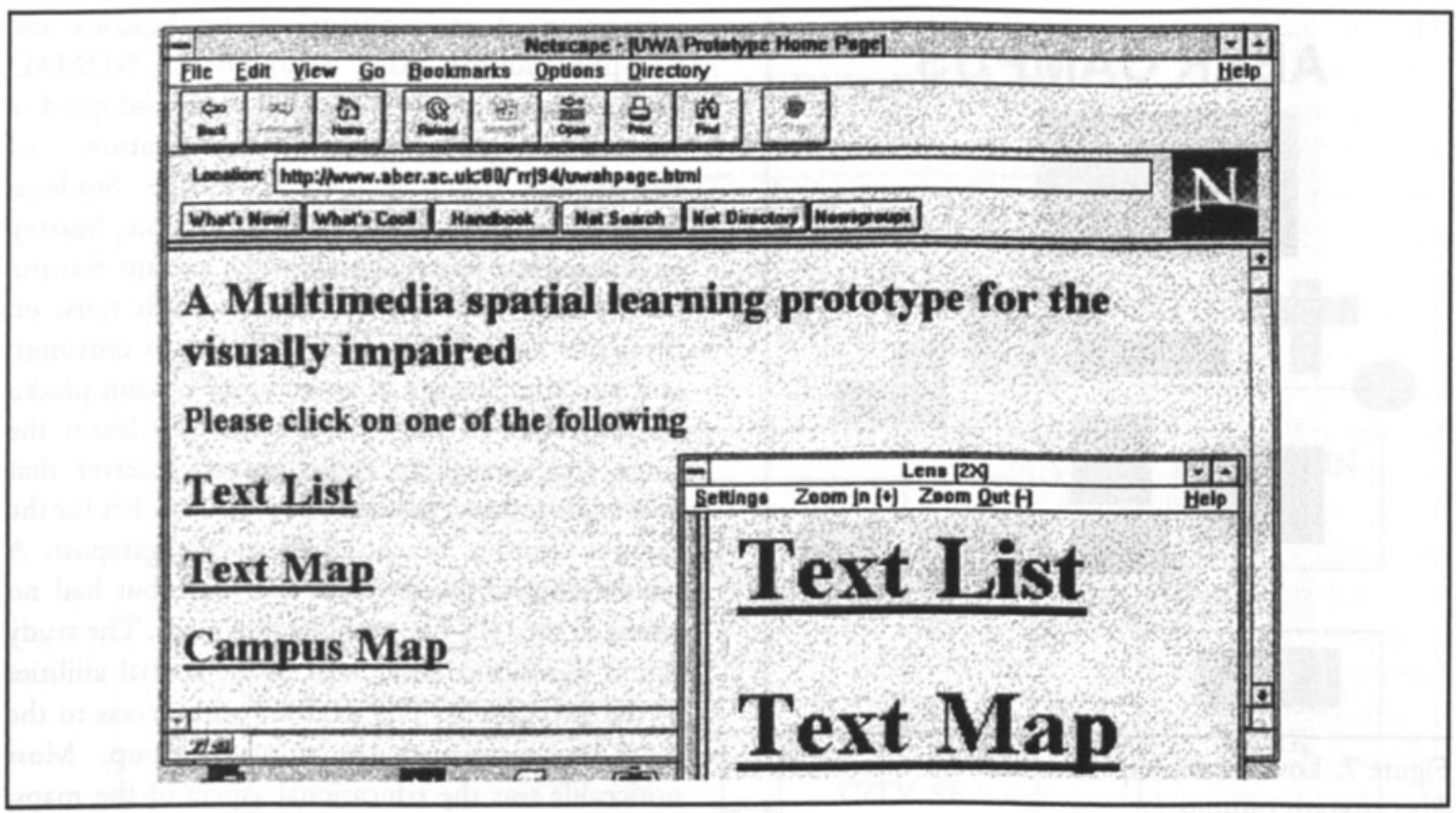

Figure 6. Screen dump of a Web hypermap 'GIS style' system.

information. A comparison and evaluation was made between different systems. The research assessed two approaches: (1) the development of techniques to allow access to spatial information for people with low vision; and (2) the development of techniques to allow access to spatial information for people with no vision.

\section{1 'GIS-style' technologies for people with low} vision

Using maps and plans available within the university, a large scale (1:2500) paper map of the Aberystwyth campus was digitized and converted into ARC/INFO format. These data were graphically manipulated using heavy line weights and bold colours to increase the map visibility. Within the attribute editing system of ARC/INFO, each building was labelled with its name (e.g. 'Huw Owen Building') and its university function (e.g. 'Main Library' or 'Institute of Earth Studies'). The graphical user interface (GUI) of ArcView means that the system is heavily reliant on vision for interaction. To counter this problem, the information was made more useable by using screen magnification and cursor enhancement technology. The GUI was stripped down and many unnecessary component buttons and menus removed. The final system worked in two modes, a low vision zoom and a pan query mode. With a single mouse click users could zoom into the area selected. By re-clicking the mouse button the user continued zooming in until the area in question filled the display. With a further click an audio file was played, 'speaking' the name of the building. Finally, a large photograph of the building was displayed. Figure 5 visually demonstrates this functionality. In the second mode, the user typed in the name or function of the building (e.g. 'Llandinam Building' or 'Earth Sciences') a map was then displayed of the campus and subsequent maps, each displayed after a mouse click, zoomed the user in to the building requested.

As such, ArcView was effectively reduced to a point-and-click hypermedia system. Users of the system expressed great interest and excitement asking: 'Can you do this for the town centre' and stating: 'Now I can experience places I would never visit.' Due to the 'simplicity' of the final slimmed down version of ArcView, and to allow optimum access and usability, it was decided to continue with the project using a Web environment.

A series of hypermap Web pages were built allowing the user to navigate between low-vision maps and spoken textual screens. Figure 6 shows a screen dump of one of the prototypes. The 


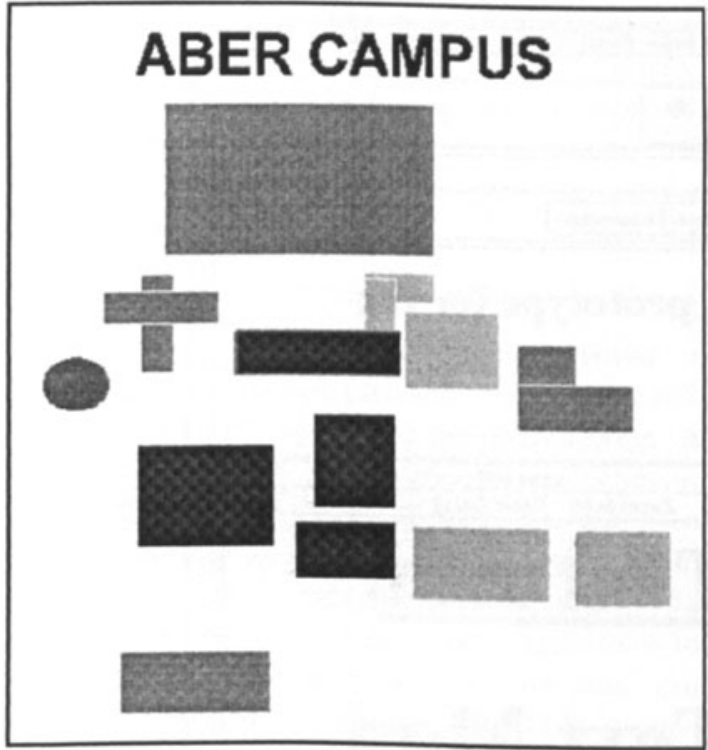

Figure 7. Low-vision map interface for Aberystwyth campus.

interface utilized large font hypertext mark-up language (HTML) and, at the bottom right, the screen magnifying software. Large scale abstracted and simplified maps were used to convey spatial information (Figure 7). An enhanced cursor was used to follow links. When a shape on the map was queried, an audio file was played describing the building. This interface enabled users to access the low-vision and spoken maps remotely. Figure 7 shows the highly generalized and abstracted map of the campus illustrating the simple spatial low-vision interface.

\section{2 'GIS style' technologies for blind people}

At the Royal National College for the Blind in Hereford, a route-learning study looked at the integration of environmental audio beacons and GIS-like auditory maps based on the NOMAD device (Jacobson 1996). The study adopted a multitask, multi-analysis investigation of respondents' cognitive map knowledge. Students explored an audio-tactile map of the route, hearing environmental audio sounds when certain features on the map were touched (such as traffic noise on the roads and the bleep of a pedestrian crossing), and also the message of an auditory beacon placed on the route. In the environment they learnt the route and carried an audio beacon receiver that relayed directional guidance such as 'rurn left for the campus' from a beacon fixed to the gatepost. A second control group learnt the route but had no access to the GIS-like audio-tactile maps. The study found significant differences in the spatial abilities of the two groups. The students with access to the maps outperformed the control group. Most noticeable was the educational aspect of the maps, sparking the imagination and interest of those who studied them. For example, one student explained: 'A tactile map is just a jumble of patterns and lines, now it talks to me, I can explore at my own pace, finding my own way.'

These studies have shown that spatial information can be clearly conveyed to blind and visually impaired people, validating earlier findings (e.g. Jacobson 1992; Jacobson and Kitchin 1995). For people without any sight, tactile information enhanced by sound assists the map-learning task and enables the retention of more spatial information than by navigation alone. The use of GIS technology and the Web to convey spatial information to people with limited sight offers a degree of user control over the information being presented, making the interaction far more flexible.

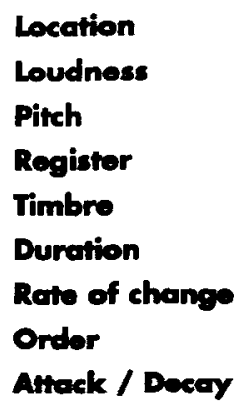

\author{
The location of a sound in a two or three-dimensional space \\ The magnitude of a sound \\ The highness or lowness (frequency) of a sound \\ The relative location of a pitch in a given range of pitches \\ The general prevailing quality or characteristic of a sound \\ The length of time a sound is for is not) heard \\ The relation between the durations of sound and silence over time \\ The sequence of sounds over time \\ The time it tokes for a sound to reach its maximum or minimum
}

Table 6. Abstract sound variables in cartographic presentations (Krygier 1994: 153). 


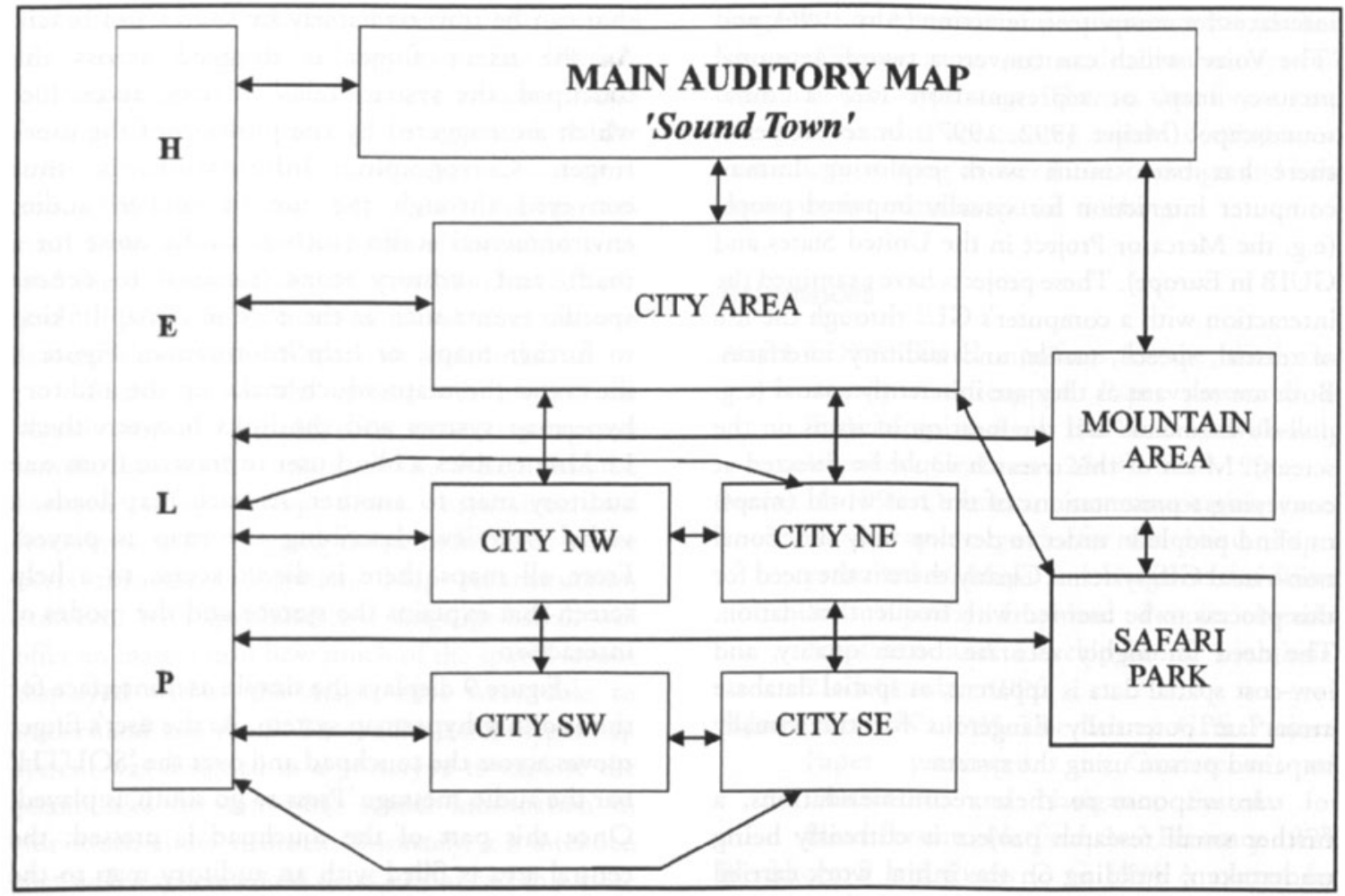

Figure 8. Proposed auditory map system - hyperlinks.

\section{A future agenda for research: The role of GIS}

It is proposed that furure research should follow two main strands. The first strand is a rigorous appraisal of the mobility and learning systems currently being developed. At present, many of these systems are being developed without an adequate understanding of the way people with visual impairments understand space (the exception to this is the work of the Santa Barbara group which has published extensively upon the cognitive understanding of space). Systems should be designed to most effectively and efficiently convey spatial relations and facilitate cognitive understanding. As such, there is a need for basic research into the cognitive understanding of geographic space by visually impaired people and to assess their ability to learn spatial information provided through different media (see Kitchin et al 1997). In particular, we know little about spatial learning from language and auditory sources. As Table 6 demonstrates, there are a number of variables that need to be understood in relation to communicating spatial information in an auditory form. Similarly, there is need for additional research into how spatial information is best communicated in both language and tactile form. Systems thus need to be tested as to their worth. It might be more worthwhile pursuing improved 'simplistic' aids and improved orientation and mobility training using sophisticated learning aids than sophisticated mobility systems where widespread use might be prohibited through poor data and fiscal constraints.

The second strand of research should be the further development and use of new interface technologies such as voice recognition, touch screens, and tactile displays. Moreover, there is a need for smaller, cheaper, lighter, less conspicuous, portable devices. Probably the most pressing need is to improve the user interface, as this is the largest barrier to successful and meaningful interactions with representations of spatial information. There have been several novel and interesting approaches which require further investigation. For example, a vibro-tactile mouse which registers the mouse's position over a desired spatial object on a map (J Nissen, personal communication 1997), tonal 
interfaces for computer interaction (Alty 1996), and 'The Voice' which can convert a two-dimensional picture, map, or representation into a 'tonal soundscape' (Meijer 1992, 1997). In recent years, there has been much work exploring human computer interaction for visually impaired people (e.g. the Mercator Project in the United States and GUIB in Europe). These project have examined the interaction with a computer's GL through the use of textual, speech, tactile, and auditory interfaces. Both are relevant as they are inherently spatial (e.g. pull-down menus and the location of icons on the screen). Much of this research could be directed at conveying representations of the real world (maps) to blind people in order to develop fully funcrional non-visual GIS systems. Clearly there is the need for this process to be user-led with frequent validation. The need for highly accurate, better quality, and low-cost spatial data is apparent, as spatial database errors are potentially dangerous for the visually impaired person using the system.

In response to these recommendations, a further small research project is currently being undertaken, building on the initial work carried out at Aberystwyth. An off-line Web site is being built which utilizes interlinking auditory maps that can be traversed solely by sound and touch. As the user's finger is dragged across the rouchpad, the system 'talks', playing audio files which are triggered by the position of the user's finger. Cartographic information is thus conveyed through the use of spoken audio, environmental audio (such as traffic noise for a road), and auditory icons (earcons) to denote specific events such as the edge of a map linking to further maps, or help/information. Figure 8 illustrates the maps which make up the auditory hypermap system and the links between them. Linking enables a blind user to traverse from one auditory map to another. As each map loads, a verbal overview describing the map is played. From all maps there is direct access to a help screen that explains the system and the modes of interaction.

Figure 9 displays the simple user interface for the auditory hypermap system. As the user's finger moves across the touchpad and over the 'SOUTH' bar the audio message 'Press to go south' is played. Once this part of the touchpad is pressed, the central area is filled with an auditory map to the south of the previous one. If no maps are available, this is verbally relayed to the user. North, west, and

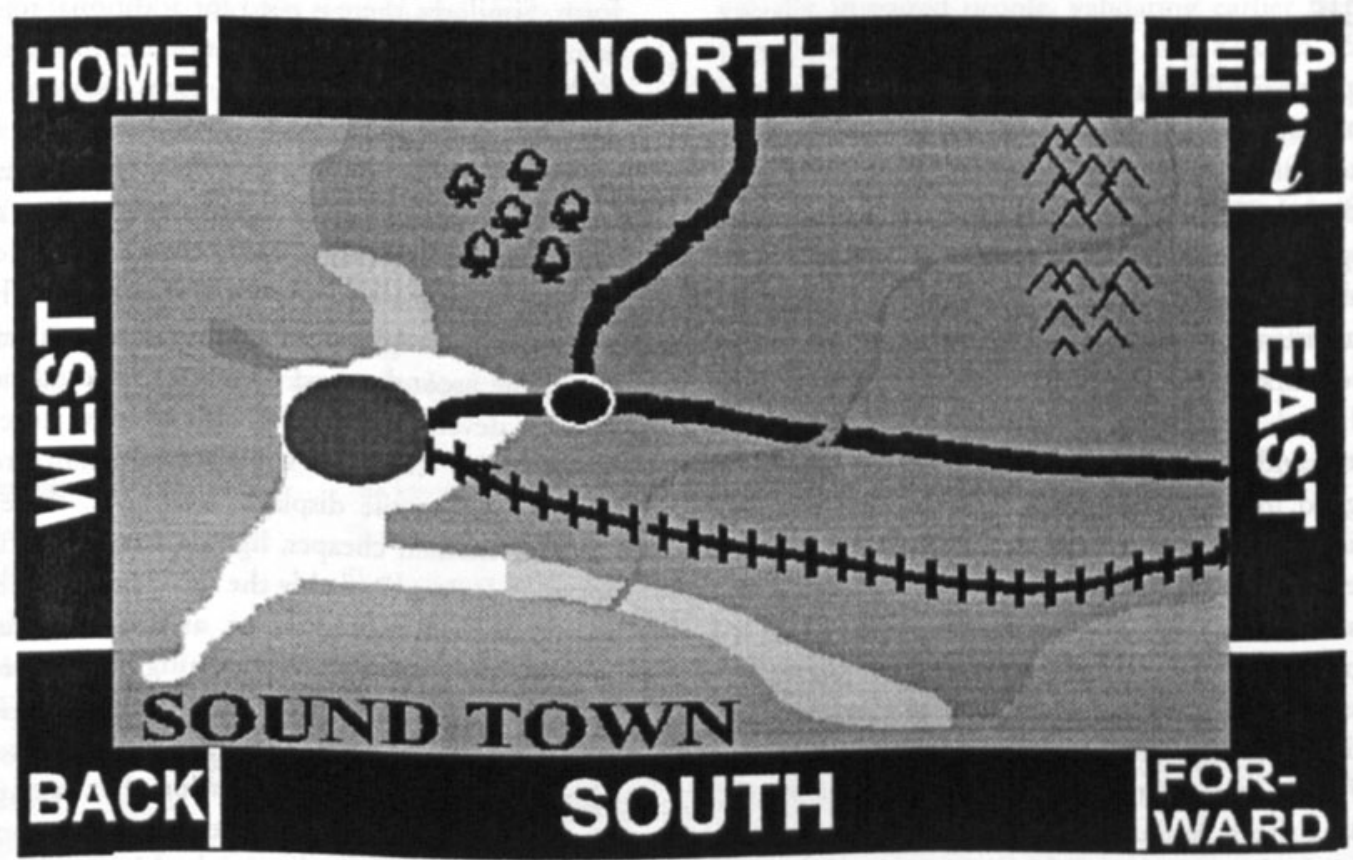

Figure 9. User interface for auditory hypermaps. 
east all work in a similar manner. 'HOME' returns the user to the main auditory map. The 'HELP' button explains how to use the system. When exiting from help the user is returned to the correct map. The ' $i$ ' button plays information about the map in view (e.g. 'This is the city area map. Downtown is in the north of the urban area, and the harbour to the west, etc.'). The 'BACK' and 'FORWARD' buttons allow the user to traverse through the 'history' of their links.

Evaluation of the system will involve ten visually impaired people. After initial training and familiarization, the utility of the system will be assessed using rating scales, semi-structured interviews, and by logging the paths followed by the users through the system. Map reconstruction exercises, both graphical and language-based, will offer an insight into how much of the spatial layout displayed within the maps users were able to understand and recall. The audio-tactile hypermap system was designed as a prototype to explore the possibilities for conveying spatial information in this 'touch-audio' manner. Ultimately, it is intended that such a system could act as a front end to a more fully functional GIS, enabling the selection and presentation of map-like information to visually impaired people. For example, to construct a map of 'made-up' town showing roads, location of crossings, and public conveniences, all at the request of the user.

\section{Conclusions}

Throughout this paper we have detailed how GIS can be adapted to help enhance the quality of life for people who are visually impaired. GIS can aid independent travel by providing sophisticated spatial data management and querying for both learning devices and orientation and mobility devices. They can be used to manage inputs from obstacle avoidance devices, positioning devices, and the user, referencing these to complex spatial databases. GIS now serve to integrate micro and macro navigation, bringing to the user information beyond their proximal environment - the next few steps. GISbased learning and orientation/navigation devices convey spatial information using language and audio-based interfaces, tactile-based interfaces and a combination of the two. It is also possible to use adapted visual interfaces employing screen magnification software for people with some residual vision. Despite these technical advances, systems remain at prototype stage. There is therefore a need for more research concerning system development, particularly relating to user interface design and how these systems relate to spatial thinking.

\section{References}

Alty J L 1996 Tonal interfaces for the blind and visually handicapped. Paper presented at Technology to Assist the Blind and Visually Impaired, Grasmere, 25-8 March 1996

Aurlan A 1996 Orientation-communication cane: An electronic guide for the blind. Paper presented at Maps and Diagrams for Blind and Visually Impaired People: Needs, Solutions, and Developments, Ljubjiana, 21-5 October 1996

Balachandran W 1995 The Surrey GPS Project. Paper presented at Conference on Orientation and Navigation Systems for Blind Persons, Hatfield, 1-2 February 1995

Blenkhorn P and Evans D G 1994 A system for reading and producing talking tactile maps. In Proceedings 9th International Conference on Technology and Persons with Disabilities, California State University, Northridge, $C A$, 13-15 March 1994

Brabyn J 1995 Orientation and navigation systems for the blind: An overview of different approaches. Paper presented at Conference on Orientation and Navigation Systems for Blind Persons, Hatfield, 1-2 February 1995

Bruce I, McKennell A, and Walker E 1991 Blind and Partially Sighted Adults in Britain: The $R N I B$ Survey, volume 1. London, Her Majesty's Stationery Office

Burrough P A 1986 Principles of Geographical Information Systems for Land Resources Assessment. Oxford, Clarendon Press

Clark-Carter D D, Heyes A D, and Howarth C I 1986 The efficiency and walking speed of visually impaired pedestrians. Engonomics, 29: 779-89

Coulson M R C 1991 Tactile-map output from geographical information systems: The challenge and its importance. International Journal of Geographical Information Systems, 5: $353-60$ 
Ellis C 1995 The Hoople Mobility Aid. Hereford, Royal National College for the Blind

Fanstone J 1995 Sound and touch: A campus GIS for the visually impaired. GIS Europe, April: 44-5

Foulke E 1983 Perception cognition and the mobility of blind pedestrians. In Potegal M (ed) Spatial Abilities: Development and Physiological Founi.tions. New York, NY, Academic Press: 55-76,

Frank A U and Mark D M 1991 Language issues for GIS. In Maguire D J, Goodchild M F, and Rhind D W (eds) Geographical Information Systems: Principles and Applications, volume 1. Harlow, Longman: 147-63

Gardiner L A and Paul R J 1993 Developing a hypertext geographic information system for the Norfolk and Suffolk Broads authority. Hypermedia, 5: 119-43

Gill J 1996 An Orientation and Navigation System for Blind Pedestrians. London, MoBIC Consortium, Royal National Institute for the Blind

Golledge R G 1993 Geography and the disabled: A survey with special reference to vision impaired and blind populations. Transactions of the Institute of British Geographers, 18: 63-85

Golledge R G 1995 Primitives of spatial knowledge. In Nyerges T L, Mark D M, and Laurini R (eds) Cognitive Aspects of Human-computer Interaction for Geographic Information Systems. Amsterdam, Kluwer Academic Publishers: 29-44

Golledge R G, Bell S, and Dougherty V J 1995 Reasoning and inference in spatial knowledge acquisition: The cognitive map as an internalized GIS. Paper presented at Annual Conference of the Association of American Geographers, San Francisco, 20-2 October 1995

Golledge R G, Loomis J M, and Klatzky R L 1994 Auditory maps as alternatives to tactual maps. Paper presented at 4th International Symposium on Maps and Graphics for the Visually Impaired, São Paulo, 20-6 February 1994
Golledge R G, Loomis J M, Klatzky K L, Flury A, and Yang X L 1991 Designing a personal guidance system to aid navigation without sight: Progress on the GIS component. International Journal of Geographical Information Systems, 5: 373-9

Golledge R, Parkes D, and Dear R 1989 NOMAD: An auditory-tactile information system for blind or vision impaired travellers. NSF USAAustralia Cooperative Science Program Final Report. Santa Barbara, CA, University of California, Department of Geography

Hill E W, Reiser J J, Hill M M, Halpin J, and Halpin R 1993 How persons with visual impairments explore novel spaces: Strategies of good and poor performers. Journal of Visual Impairment and Blindness, 87: 295-301

Hinton R A L 1993 Tactile and audio-tactile images as vehicles for learning. Non-visual Human Computer Interaction, 228: 169-79

Jacobson R D 1992 Spatial cognition through tactile mapping. Swansea Geographer, 29: 79-88

Jacobson R D 1996 Talking tactile maps and environmental audio beacons: An orientation and mobility development tool for visually impaired people. Paper presented at Maps and Diagrams for Blind and Visually Impaired People: Needs, Solutions, and Developments, Ljubjiana, 21-5 October 1996

Jacobson R D and Kitchin R M 1995 Assessing the configurational knowledge of people with visual impairments and blindness. Swansea Geographer, 32: 14-24

Joffee E 1987 Role of electronic travel aids: Field applications of the Russell Pathsounder. Journal of Visual Impairment and Blindness, October: 389-90

Kay S 1973 The sonic glasses evaluated. The New Outlook for the Blind, 67: 7-11

Kitchin R M 1994 Cognitive maps: What are they and why study them? Journal of Environmental Psychology, 14: 1-19 
Kitchin R M and Jacobson R D 1997 Techniques to collect and analyse the cognitive map knowledge of people with visual impairments or blindness. Journal of Visual Impairment and Blindness, 91: 360-76

Kitchin R M, Blades M, and Golledge R G 1997 Understanding spatial concepts at the geographic scale without the use of vision. Progress in Human Geography, 21: 225-42

Krygier J B 1994 Sound and geographic visualization. In MacEachren $A M$ and Fraser Taylor D R (eds) Visualization in Modern Cartography. New York, NY, Pergamon Press: 149-66

Landau B and Jackendoff R 1993 'What' and 'where' in spatial language and cognition. Behavioural and Brain Sciences, 16: 217-65

Lee D 1996 Sensor fusion in mobility aids. Paper presented at Technology to Assist the Blind and Visually Impaired, Grasmere, 25-8 March 1996

Linsey T K and Raper J F 1993 HyperArc: A taskoriented hypertext GIS interface. International Journal of Geographical Information Systems, 7: 435-52

Loomis J M, Hernert C, and Cincinelli J G 1990 Active localization in virtual sounds. Journal of the Acoustical Society of America, 88: 1757-64

Loomis J M, Golledge R G, and Klatzky R L 1995 Personal guidance system. Paper presented at Conference on Orientation and Navigation Systems for Blind Persons, Hatfield, 1-2 February 1995

Meijer P B L 1992 An experimental system for auditory image representation. Institute of Electrical and Electronics Engineers Transactions on Biomedical Engineering, 39: 112-21

Meijer P B L 1997 Soundscapes from the voice: Introduction and overview [see http://ourworld.compuserve.com/homepages/Pe ter_Meijer/ voicover.htm]

Milleret-Raffort F 1995 Some cognitive and technical aspects of hypermaps. In Nyerges T L, Mark D M, and Laurini R (eds) Cognitive Aspects of Human-computer Interaction for Geographic Information Systems. Amsterdam, Kluwer Academic Publishers: 195-206
Parkes D 1988 NOMAD: An audio-tactile tool for the acquisition, use, and management of spatially distributed information by partially sighted and blind people. In Proceedings Second International Conference on Maps and Graphics for Visually Disabled People Nottingham, 20-2 July 1988. Nottingham, Nottingham University: 24-9

Parkes D 1996 The graphics solution. In Proceedings Maps and Diagrams for Blind and Visually Impaired People: Needs, Solutions, and Developments, Ljubjiana, 21-5 October 1996

Passini R and Proulx G 1988 Wayfinding without vision. An experiment with congenitally totally blind people. Environment and Behaviour, 20: 227-52

Petrie H, Johnson V, Strothotte T, Raab A, Fritz S, and Michel R 1996 MoBIC: Designing a travel aid for blind and elderly people. Journal of Navigation, 49: 45-52

Savidis A and Stephanidis C 1995 Building nonvisual interaction through the development of the rooms metaphor. In Proceedings CHI 95 Conference on Human Factors in Computing Systems, Denver, CO, 7-11 May 1995. Graphical Uscr Interfaces for Blind People Consortium: 244-5

Spencer C, Blades M, and Morsley K 1989 The Child in the Physical Environment: The Development of Spatial Knowledge and Cognition. New York, NY, John Wiley \& Sons, Inc.

Spungin S J 1985 Corridors of insensitivity: Technology and blind persons. Journal of Visual Impairment and Blindness, March: 113-16

Strothotte T, Fritz S, Michel R, Raab A, Petrie H, Johnson V, Reichert L, and Schalt A 1996 Development of dialogue systems for a mobility aid for blind people: Initial design and usability testing. Paper presented at Assets 96, Vancouver, 15-17 April 1996

Tatham A F 1991 The design of tactile maps: Theoretical and practical considerations. In Rybaczak $K$ and Blakemore $M$ (eds) Proceedings International Cartographic Association: Mapping the Nations. London, International Cartographic Association: $157-66$ 
Webspeak 1995 The pwWEb Speak Project. [see http://www.prodworks.com/pwwebspeak.htm]

Uslan M M, Russell L, and Weiner C 1988 A 'musical pathway' for spatially disorientated blind residents in a skilled nursing facility. Journal of Visual Impairment and Blindness, January: 21-4 